Adi Moh. Rizal dan Indah Nurhayati :Pengolahan Limbah Bahan Berbahaya Dan Beracun (B3) Dengan Insinerator Tipe Reciprocating Grate Incinerator

\title{
PENGOLAHAN LIMBAH BAHAN BERBAHAYA DAN BERACUN (B3) DENGAN INSINERATOR TIPE RECIPROCATING GRATE INCINERATOR
}

\author{
Adi Moh. Rizal ${ }^{1)}$ dan Indah Nurhayati ${ }^{1)}$ \\ ${ }^{1)}$ Program Studi Teknik Lingkungan; Fakultas Teknik Sipil dan Perencanaan \\ Universitas PGRI Adi Buana Surabaya \\ Email: adimboys@gmail.com
}

\begin{abstract}
Abstrak
Penelitian ini bertujuan untuk mengetahui kadar $\mathrm{CO}, \mathrm{CO}_{2}$ dan efisiensi pembakaran serta pengaruh berat limbah $\mathrm{B} 3$ terhadap kadar $\mathrm{CO}, \mathrm{CO}_{2}$, dan efisiensi pembakaran insinerator tipe reciprocating grate incinerator dalam pengolahan limbah B3. Variabel penelitian ini adalah berat limbah B3 yang dibakar yaitu tanpa limbah $(0 \mathrm{~kg})$ sebagai $\mathrm{kontrol,} 150 \mathrm{~kg}$, dan $300 \mathrm{~kg}$. Jenis limbah B3 yang dibakar yaitu sludge WWTP, majun dan sarung tangan terkontaminasi, dan limbah medis dengan perbandingan berat 3:2:1. Pengukuran kadar $\mathrm{CO}$ dan $\mathrm{CO}_{2}$ dilakukan dengan menggunakan alat Gas Analyzer Bacarach PCA3. Efisiensi pembakaran diperoleh dengan membandingkan kadar $\mathrm{CO}_{2}$ dan kadar $\mathrm{CO}$ hasil pembakaran pada suhu ruang bakar I antara $(600-800)^{\circ} \mathrm{C}$ dan ruang bakar II minimal $1200^{\circ} \mathrm{C}$ dengan lama pembakaran 1 jam. Hasil dari penelitian ini adalah kadar CO hasil pembakaran limbah $B 3$ pada kondisi tanpa limbah $(0 \mathrm{~kg}), 150 \mathrm{~kg}$ dan $300 \mathrm{~kg}$ masih dibawah nilai ambang batas sesuai Kep-03/ Bapedal/ 09/1995 yaitu $100 \mathrm{mg} / \mathrm{Nm}^{3}$. Semakin besar berat limbah B3 sampai kapasitas maksimum yang dibakar, didapatkan kadar CO yang semakin menurun sedangkan kadar $\mathrm{CO}_{2}$ semakin meningkat. Efisiensi pembakaran pada insinerator tipe reciprocating grate incinerator dengan variasi berat limbah $B 3$ (tanpa limbah, $50 \mathrm{~kg}$, dan $100 \mathrm{~kg}$ ) yang dibakar semuanya adalah 99,99\%, kondisi ini sesuai dengan persyaratan yang ditetapkan oleh Kep03/BAPEDAL/09/1995 yaitu 99,99\%. Efisiensi pembakaran pada insinerator tipe reciprocating grate incinerator tidak dipengaruhi oleh variasi berat limbah B3 yang dibakar.
\end{abstract}

Kata Kunci: Limbah B3, Insinerator, Efisiensi Pembakaran, Kadar CO.

\begin{abstract}
This study aims to determine the levels of $\mathrm{CO}, \mathrm{CO}_{2}$ and $\mathrm{EP}$ as well as the heavy influence of $\mathrm{B} 3$ waste to levels of $\mathrm{CO}, \mathrm{CO}_{2}$, and the combustion efficiency of the incinerator type reciprocating grate incinerator in wastewater treatment B3. This research variable heavy use of B3 waste incinerators that burned without waste $(0 \mathrm{~kg})$ as a control, $150 \mathrm{~kg}$ and $300 \mathrm{~kg}$. Type B3 waste is burned that WWTP sludge, contaminated rags and gloves, and medical waste with a weight ratio of 3: 2: 1. Methods of data collection levels of $\mathrm{CO}$ and $\mathrm{CO}_{2}$ measurements done using PCA3 Bacarach Gas Analyzer. The combustion efficiency is obtained by comparing the levels of $\mathrm{CO}_{2}$ and $\mathrm{CO}$ the first chamber combustion temperature between $(600-800)^{\circ} \mathrm{C}$ and second chamber of at least $1200^{\circ} \mathrm{C}$ with long burning 1 hour. The results of this study are the result of combustion CO level B3 waste in conditions without waste $(0 \mathrm{~kg}), 150 \mathrm{~kg}$ and $300 \mathrm{~kg}$ is still below the threshold value corresponding Kep-03 / BAPEDAL / 09/1995 is $100 \mathrm{mg} / \mathrm{Nm}^{3}$. The greater the weight of waste B3 until maximum capacity is burned, it was found that $\mathrm{CO}$ levels decreased while increasing $\mathrm{CO}_{2}$ levels. The combustion efficiency in the incinerator type Reciprocating grate incinerator with weight variation B3 (without waste, $50 \mathrm{~kg}$ and $100 \mathrm{~kg}$ ) were burnt respectively 99.99\% in accordance with the requirements set by Kep-03 / BAPEDAL/09/1995 is 99.99\%. The combustion efficiency in the incinerator type Reciprocating grate incinerator is not affected by variations in weight of B3 waste is burned.
\end{abstract}

Keywords: B3 waste, Incinerator, Combustion Efficiency, CO level. 


\section{PENDAHULUAN}

Menurut PP No. 101 tahun 2014

Tentang Pengeloaan Limbah Bahan Berbahaya dan Beracun, yang dimaksud dengan bahan berbahaya dan beracun (B3) adalah zat, energy dan/atau komponen lain yang karena sifat, konsentrasi dan/atau jumlahnya, baik secara langsung maupun tidak langsung dapat mencemari dan/atau merusak lingkungan hisup, dan/atau membahayakan lingkungan hidup, kesehatan, serta kelangsungan hidup manusia dan makhluk hidup lain. Limbah B3 adalah sisa suatu usaha dan/atau kegiatan yang mengandung $\mathrm{B} 3$.

Limbah B3 dapat berasal dari B3 kadaluwarsa, B3 tumpah, B3 yang tidak memenuhi spesifikasi produk yang akan dibuang, bekas kemasan B3 dan limbah B3 dari sumber yang spesifik. Karakteristik limbah B3 adalah mudah meledak, mudah menyala, reaktif, infeksius, korosif dan/atau beracun(PP.No. 101, 2014).

Proses penyimpanan sementara limbah B3 sampai pengangkutan ke pengolah akhir harus mengikuti beberapa persyaratan penyimpanan dan pengangkutan. Hal ini dimaksudkan untuk menjamin keamanan dan keselamatan proses penyimpanan dan pengangkutan mengingat besarnya potensi bahaya dari beberapa limbah B3. Persyaratan penyimpanan dan pengangkutan dapat diikuti dengan melihat dari karakteristik dan potensi bahaya dari setiap limbah B3. Karakteristik limbah B3 dijadikan landasan yang digunakan untuk menentukan perlakuan dalam proses penyimpanan sementara dan pengemasan pada saat akan dilakukan proses pengangkutan (Kepmen. Tenaga Kerja No. 187, 1999).

Limbah padat B3 tidak diperbolehkan dibuang langsung ke tempat pembuangan akhir limbah domesti dan harus diolah terlebih dahulu(Girsang, 2013). Pengolahan limbah B3 dalah proses untuk mengurangi dan/atau menghilangkan sifat bahaya sifat bahaya dan/atau sifat racun (PP, 2014). Pemilihan jenis pengolahan limbah B3 tergantung pada karakteristik dan kandungan limbah tersebut. Menurut KEP-03/BAPEDAL/09/1995 bahwa pengolahan limbah B3, adalah proses untuk mengubah jenis, jumlah dan karakteristik limbah B3 menjadi tidak berbahaya dan/atau tidak beracun dan/atau immobilisasi limbah B3 sebelum ditimbun dan/atau memungkinkan agar limbah B3 dimanfaatkan kembali (daur ulang). Proses pengolahan limbah B3 dapat dilakukan secara pengolahan fisika dan kimia, stabilisasi/solidifikasi, dan insenerasi.

Menurut KEP-03/BAPEDAL/09/1995, proses pengolahan secara fisika dan kimia bertujuan untuk mengurangi daya racun limbah B3 dan/atau menghilangkan sifat/karakteristik limbah B3 dari berbahaya menjadi tidak berbahaya. Proses pengolahan secara stabilisasi/solidifikasi bertujuan untuk mengubah watak fisik dan kimia limbah B3 dengan cara penambahan senyawa pengikat B3 agar pergerakan senyawa B3 ini terhambat atau terbatasi dan membentuk massa monolit dengan struktur yang kekar. Proses pengolahan secara insenerasi bertujuan untuk menghancurkan senyawa B3 yang terkandung di dalamnya menjadi senyawa yang tidak mengandung B3.

Pengolahan limbah B3 dapat dilakukan dengan beberapa proses yaitu; (a) Proses secara kimia, meliputi proses redoks, elektrolisa, netralisasi, pengendapan, stabilisasi, adsobsi, penukaran ion dan pirolisis, (b) Proses secara fisika, meliputi proses pembersihan gas, pemisahan cairan dan penyisihan komponenkomponen spesifik dengan metode adsobsi, kristalisasi, dialisa, elektrodialisa, evaporasi, leaching, reverse osmosis, solvent extraction dan stripping, (c) Proses stabilisas/solidifikasi, dengan tujuan untuk mengurangi potensi racun dan kandungan limbah B3 dengan cara membatasi daya larut, penyebaran, dan daya racun sebelum limbah dibuang ke tempat penimbunan akhir. Bahan-bahan yang sering digunakan untuk proses stabilisasi /solidifikasi (bahan aditif) antara lain gypsum, lempung, abu terbang sebagai bahan pencampur dan semen, kapur dan tanah liat sebagai bahan perekat/pengikat, (d) Proses insinerasi, dilakukan dengan cara melakukan pembakaran limbah menggunakan alat khusus insinerator. Pengolahan limah B3 dengan cara insenerasi, efisiensi pembakarannya harus mencapai 99,99\% atau lebih. Artinya, jika suatu materi limbah B3 ingin dibakar (insinerasi) dengan berat $100 \mathrm{~kg}$, maka abu sisa pembakaran tidak boleh melebihi $0,01 \mathrm{~kg}$ atau $10 \mathrm{gr}$. Baku mutu efisiensi penghancuran dan penghilangan (DRE) yang disyaratkan adalah sebagai berikut : (a) Baku mutu DRE untuk Principle Organic Hazard Constituent (POHCs) 99,99\%, (b) Baku mutu DRE untuk Polyclorinated Biphenyl (PCBs) 99,9999\%, (c) Baku mutu DRE untuk Polyclorinated Dibenzofurans 99,9999\%, dan (c) Baku mutu DRE untuk Polyclorinated Dibenso-P-dioxins 99,9999\%. (KEP-03/BAPEDAL/09/1995) 
Tingginya efisiensi pembakaran dalam insenerator diperoleh dari hubungan antara suhu ruang bakar yang khusus dan adanya pembakar otomatis (burner) dengan bahan bakar dari minyak bakar atau gas alam (LPG). Baku mutu emisi udara Karbon Monoksida (CO) yang dipersyaratkan berdasarkan Kep-03/ Bapedal/ 09/ 1995 dilihat dari efisiensi pembakarannya (EP), yaitu sama atau lebih besar dari 99,99\% . Efisiensi pembakaan (EP) adalah kemampuan insinerator untuk mengubah senyawa organik pada limbah B3 menjadi $\mathrm{CO}_{2}$ dan $\mathrm{H}_{2} \mathrm{O}$. Efisiensi pembakaran (EP) dihitung dengan menggunakan rumus sebagai berikut :

\section{Keterangan:}

$$
\mathrm{EP}=\frac{C_{2}}{C_{2}+C} \times 100 \%
$$

$\mathrm{EP}=$ Efisiensi Pembakaran (\%)

$\mathrm{CO}_{2}=$ Konsentrasi emisi $\mathrm{CO}_{2}$ di exhaust $\left(\mathrm{mg} / \mathrm{NM}^{3}\right)$

$\mathrm{CO}=$ Konsentrasi emisi $\mathrm{CO}$ di exhaust $\left(\mathrm{mg} / \mathrm{NM}^{3}\right)$

Salah satu teknologi pengolahan limbah

B3 adalah dengan proses thermal. Proses thermal (insinerasi) adalah adalah salah satu alternatif dalam mengolah limbah B3. Teknologi insenerasi bukan merupakan solusi akhir dari pengolahan limbah B3, karena pada dasarnya hanya memindahkan limbah dari bentuk padat yang kasat mata ke bentuk gas yang tidak kasat mata. Pengolahan limbah padat dengan insenerasi dapat mengurangi volume limbah sekitar $90 \%$ dan berat limbah sekitar $75 \%$. Insenerasi mempunyai beberapa kelebihan, yaitu sebagian dari komponen limbah B3 dapat dihancurkan dan limbah berkurang dengan cepat. Penggunaan insinerator yang tidak optimum mempunyai beberapa kerugian diantaranya: kerusakan alat, boros bahan bakar, tingginya residu pasca bakar timbul bau tidak sedap dan timbul partikulat yang menyebabkan pencemaran bagi lingkungan (Nurhayati, 2011).

Insinerator merupakan teknologi pengolahan limbah medis yang dapat memusnahkan komponen berbahaya. Volume limbah yang dapat direduksi $5-15 \%$ berupa abu selainnya menghasilkan energi. Hal tersebut dapat diperoleh secara bersamaan apabila suhu pembakaran $1200^{0} \mathrm{C}$, sehingga insinerasi dianggap sebagai salah satu cara mengolah limbah yang ideal (Reingart, 1995 dalam Girsang 2013).

Jenis limbah yang dapat dimusnahkan dengan alat insinerator adalah: (a) Limbah infeksius dari rumag sakit, (b) Limbah Industri, terbagi atas limbah padat, obat kadaluarsa pada industri farmasi, produk sisa pada industri makanan, sabun, sampo dan lain-lain, ampah kemasan, adonan permen yang mengeras dan tidak dapat digunakan pada industri permen, majun atau potongan kain pada industri tekstil, sisa tembakau dan produk reject pada industri rokok, karet- karet bekas dan sudah tidak bisa digunakan pada industri karet, kerak cat yang sudah mengeras pada industri otomotif, (c) Limbah sludge dari proses pengolahan limbah cair (Wastewater Treatment Sludge) dari berbagai jenis industry.

Keuntungan dari pengolahan limbah dengan proses insinerasi adalah : (a) Proses insinerasi dapat mengurangi volume dan berat limbah secara signifikan, (b) Limbah dapat ditangani dalam waktu yang relatif lebih singkat, (c) Area yang dibutuhkan relatif lebih kecil, (c) Pembuangan gas hasil pembakaran dapat dikontrol secara efektif untuk meminimumkan pengaruh pada lingkungan. Pengolahan limbah dengan insenerator juga mempunyai beberapa kekurangan yaitu : (a) Modal awal yang cukup besar, (b) Biaya operasional cukup tinggi, (c) Masih memerlukan langkah-langkah lanjutan pada akhir proses (abu dan sisa pembakaran) di buang ke lahan lain

Insinerator sebelum digunakan atau dioperasikan secara terus-menerus harus mendapatkan ijin dari Kementrian Lingkungan Hidup (KLH). Insinerator tersebut diuji kinerjanya dalam pengolahan limbah B3 sehingga tidak menghasilkan gas buang yang berbahaya bagi lingkungan. Kinerja insinerator secara mudah dapat dinilai salah satunya melalui uji efisiensi pembakaran insinerator. Tujuan Efisiensi pembakaran pada insinerator untuk mengetahui tingkat kesempurnaan pembakaran senyawa organik pada limbah B3 menjadi $\mathrm{CO}_{2}$ dan $\mathrm{H}_{2} \mathrm{O}$ yang diperoleh dengan membandingan kadar $\mathrm{CO}$ dengan $\mathrm{CO}_{2}$ pada titik sampling yang telah ditetapkan (Kep-03/ Bapedal/ 09/ 1995).

PT X yang berlokasi di Mojokerto merupakan perusahan pengolahan limbah B3 dengan menggunakan insinerator tipe Reciprocating grate incinerator yang memiliki kapasitas pembakaran $300 \mathrm{~kg} / \mathrm{jam}$. Insinerator tipe ini memiliki kelebihan dalam pengumpanan limbah dan pengeluaran abu secara otomatis dan menggunakan 2 ruang pembakan sehingga pembakarannya lebih sempurna serta menggunakan Wet Scrubber (Air Pollution Control) untuk menangkap partikel/abu dan 
gas-gas yang bersifat asam sehingga menghasilkan gas buang emisi yang lebih aman dan tidak membahayakan lingkungan. Akan tetapi, insinerator ini belum memiliki ijin operasional dari KLH sehingga insinerator tersebut perlu diuji kinerjanya sesuai Kep-03/ Bapedal/ 09/ 1995 dengan salah satu persyaratan adalah efisiensi pembakaran. Tujuan dari penelitian ini adalah untuk mengetahui kadar $\mathrm{CO}$ dan efisiensi pembakarana serta pengaruh berat limbah B3 terhadap kadar $\mathrm{CO}, \mathrm{CO}_{2}$, dan efisiensi pembakaran insinerator tipe Reciprocating grate incinerator dalam pengolahan limbah B3. Manfaat dari penelitian ini adalah memberi informasi kepada industri dan masyarakat tentang kinerja insinerator tipe Reciprocating grate incinerator dalam pengolahan limbah B3.

Tujuan dari penelitian ini adalah untuk mengetahui kadar $\mathrm{CO}, \mathrm{CO}_{2}$ dan efisiensi pembakaran yang dihasilkan insinerator tipe reciprocating grate incinerator dalam pengolahan limbah B3, untuk mengetahui pengaruh berat limbah $\mathrm{B} 3$ terhadap kadar $\mathrm{CO}$ dan $\mathrm{CO}_{2}$ dan efisiensi pembakaran pada insinerator tipe Reciprocating grate incinerator dalam pengolahan limbah B3

\section{METODE}

Penelitian ini dilakukan di PT X di Mojokerto Jawa Timur yang bergerak dalam bidang pengolahan limbah B3. Objek dari penelitian ini adalah limbah B3.

\section{Variabel Penelitian}

Variabel bebas pada penelitian ini adalah berat limbah B3 yang dibakar, yaitu pada saat kosong $(0 \mathrm{~kg})$, normal $(150 \mathrm{~kg})$, overload $(300 \mathrm{~kg})$ dengan komposisi limbah yaitu sludge Waste Water Treatment Plan (WWTP), majun terkontaminasi, dan limbah medis dengan perbandingan 3:2:1. Variabel terikat pada penelitian adalah efisiensi pembakaran (kadar $\mathrm{CO} 2$ dan CO di exhaust). Variabel kontrol pada penelitian adalah jenis limbah B3 yang dibakar dan lama pembakaran.

\section{Populasi dan Sampel}

Populasi dalam penelitian ini adalah limbah B3. Sampel yang diteliti merupakan limbah B3 yang terdiri dari sludge waste water treatment (WWT) industri makanan, dan limbah medical yang berupa kasa, perban, labu, obat kadaluarsa dan sampel laboratorium, botol plastik/kaca dan jaringan tubuh.

\begin{abstract}
Alat dan Bahan
Alat yang digunakan adalah gas Analyzer Bacarach PCA3, apex isocinetic, insinerator tipe Reciprocating grate incinerator (first chamber, second chamber, wet scrubber, cyclon, burner, dan blower), dan timbangan. Bahan yang digunakan yaitu majun, sarung tangan kain dan karet, kertas dan plastik terkontaminasi $\mathrm{B} 3$, sludge waste water treatment (WWT) industri makanan, dan limbah medical yaitu kasa, perban, labu, obat kadaluarsa dan sampel laboratorium, botol plastik/kaca dan jaringan tubuh.
\end{abstract}

\section{Langkah Penelitian}

1. Menyiapkan sampel limbah B3 yang diperoleh dari beberapa industri dan rumah sakit yaitu sludge WWTP, majun dan sarung tangan terkontaminasi, dan limbah medis.

2. Menimbang berat limbah B3 sesuai dengan variabel penelitian yaitu tanpa beban atau sebesar $0 \mathrm{~kg}$ (limbah B3 $0 \%$, normal atau sebesar $150 \mathrm{~kg}$ (limbah B3 50\%), dan maksimum atau sebesar $300 \mathrm{~kg}$ (limbah B3 100\%). Perbandingan berat limbah sludge WWTP, majun dan sarung tangan terkontaminasi, dan limbah medis yaitu 3:2:1. Limbah B3 yang sudah ditimbang dimasukkan plastic.

3. Membakar limbah yang sudah dimasukkan kantong plastik dengan incinerator tipe Reciprocating grate incinerator selama 1 jam dengan suhu antara (600-800) ${ }^{\circ} \mathrm{C}$.

4. Mengukur kadar kadar $\mathrm{CO}$ dan $\mathrm{CO}_{2}$ selama proses pembakaran limbah B3 menggunakan alat gas analyzer. Pembacaan hasil akhir kadar CO dan $\mathrm{CO}_{2}$ pada saat angka pada alat tersebut menunjukkan nilai yang stabil.

5. Pengukuran kadar $\mathrm{CO}$ dan $\mathrm{CO}_{2}$ dilakukan pengulangan sebanyak 3 kali.

\section{Metode Analisis Data}

Data hasil penelitian yang berupa kadar CO dan $\mathrm{CO}_{2}$ kemudian dihitung efisiensi pembakarnnya dengan menggunakan rumus.

$$
\mathrm{EP}=\frac{C_{2}}{C_{2}+C} \times 100 \%
$$

Keterangan:

$\mathrm{EP}=$ Efisiensi Pembakaran (\%)

$\mathrm{CO}_{2}=$ Konsentrasi emisi $\mathrm{CO}_{2}$ di exhaust $\left(\mathrm{mg} / \mathrm{NM}^{3}\right)$ 
Adi Moh. Rizal dan Indah Nurhayati :Pengolahan Limbah Bahan Berbahaya Dan Beracun (B3) Dengan Insinerator Tipe Reciprocating Grate Incinerator

$\mathrm{CO}=$ Konsentrasi emisi $\mathrm{CO}$ di exhaust $\left(\mathrm{mg} / \mathrm{NM}^{3}\right)$

Data kadar $\mathrm{CO}$ dan $\mathrm{CO}_{2}$ dan efisiensi pembakaran dianalisis dengan pendekatan grafik.

\section{HASIL DAN PEMBAHASAN}

\section{Pengaruh Berat Limbah $\mathbf{B 3}$ Terhadap Kadar $\mathrm{CO}$ dan Kadar $\mathrm{CO}_{2}$}

Kadar $\mathrm{CO}$ dan $\mathrm{CO}_{2}$ dari pembakaran limbah B3 dengan menggunakan insenerator tipe reciprocating grate incinerator disajikan dalam tabel 1.

Tabel 1. Kadar $\mathrm{CO}$ dan $\mathrm{CO}_{2}$ Pembakaran Limbah B3 Menggunakan Insenerator Tipe Reciprocating Grate Incinerator

\begin{tabular}{llllll}
\hline $\begin{array}{l}\text { Berat } \\
(\mathrm{kg})\end{array}$ & Replikasi & $\begin{array}{l}\mathrm{CO} \\
\left(\mathrm{mg} / \mathrm{NM}^{3}\right)\end{array}$ & $\begin{array}{l}\mathrm{CO}_{2} \\
\left(\mathrm{mg} / \mathrm{NM}^{3}\right)\end{array}$ & $\begin{array}{l}\mathrm{EP} \\
(\%)\end{array}$ & $\begin{array}{l}\mathrm{NAB} \\
(\%)\end{array}$ \\
\hline \multirow{3}{*}{0} & 1 & 18.59 & 128911.9 & 99.99 & \\
& 2 & 19.19 & 130182 & 99.99 & 99.99 \\
& 3 & 18.52 & 125000.2 & 99.99 & \\
& Rerata & 18.8 & 128031.4 & 99.99 & \\
& 1 & 15.5 & 131969.7 & 99.99 & \\
150 & 2 & 15.77 & 130947.3 & 99.99 & 99.99 \\
& 3 & 15.6 & 131086 & 99.99 & \\
& Rerata & 15.6 & 131334.3 & 99.99 & \\
& 1 & 12.71 & 146124 & 99.99 & \\
300 & 2 & 12.4 & 139676.2 & 99.99 & 99.99 \\
& 3 & 12.49 & 144152.6 & 99.99 & \\
& Rerata & 12.5 & 143317.6 & 99.99 & \\
\hline
\end{tabular}

Pengaruh berat limbah B3 terhadap kadar CO pada pembakaran limbah B3 dengan insenerator tipe reciprocating grate incinerator dapat dilihat pada gambar 1 .

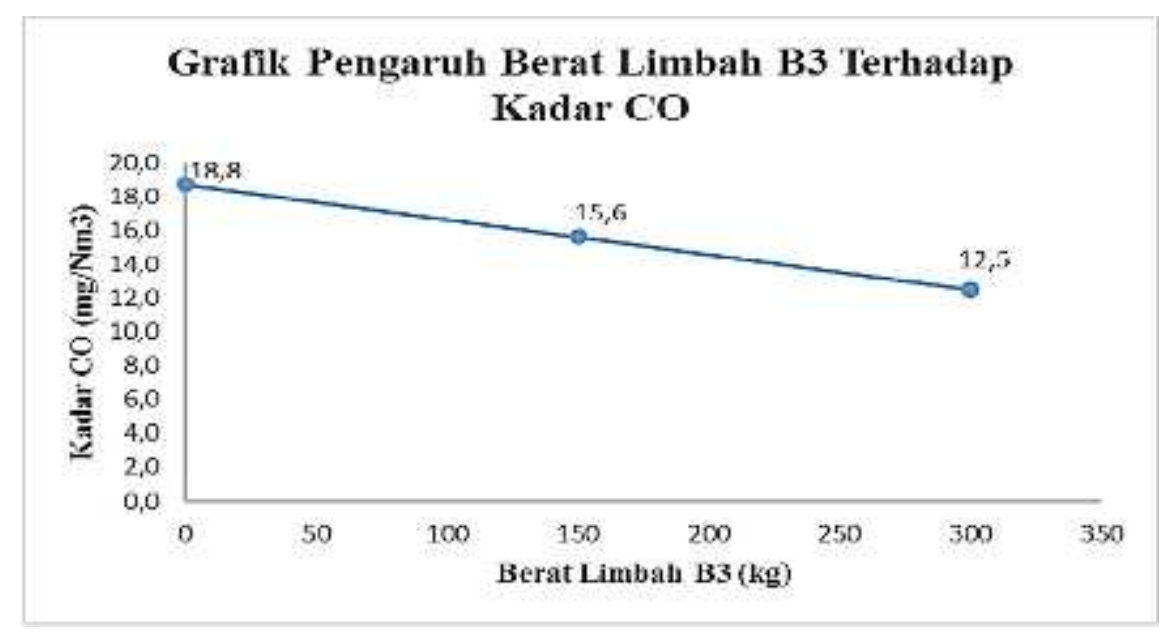

Gambar 1. Pengaruh Berat Limbah B3 Terhadap Kadar CO

Pengaruh berat limbah $\mathrm{B} 3$ terhadap kadar $\mathrm{CO}_{2}$ pada pembakaran limah B3 menggunakan insenerator tipe reciprocating grate incinerator dapat dilihat pada gambar 2. Dari gambar 2 dapat dilihat bahwa semakin tinggi berat limbah B3 yang dibakar, maka semakin tinggi kadar $\mathrm{CO}_{2}$ yang dihasilkan.
Dari gambar 1menunjukan hasil bahwa kadar rata-rata $\mathrm{CO}$ pada berat limbah $\mathrm{B} 30 \mathrm{~kg}$ sampai $300 \mathrm{~kg}$ mengalami penurunan dibawah nilai ambang batas baku mutu Kep-03/ Bapedal/ 09/1995 yaitu $100 \mathrm{mg} / \mathrm{Nm}^{3}$. Dengan demikian pembakaran limbah B3 dengan berat $0 \mathrm{~kg}, 150$ $\mathrm{kg}$, dan $300 \mathrm{~kg}$ dengan insinerator reciprocating grate incinerator menghasilkan kualitas emisi 
gas buang CO yang seusia dengan Kep-03/ Bapedal/ 09/1995.

Hal ini menunjukkan bahwa semakin besar berat limbah B3 sampai kapasitas maksimum, maka pembakarannya semakin sempurna dan semakin baik. Dari hasil pembacaan pada gambar 1 dan gambar 2 dapat dapat disimpulkan bahwa semakin tinggi berat limbah B3 yang dibakar sampai kapasitas maksimum, yaitu $300 \mathrm{~kg}$ didapatkan kadar $\mathrm{CO}$ yang semakin menurun sedangkan kadar $\mathrm{CO}_{2}$ semakin meningkat. besarnya kadar $\mathrm{CO}_{2}$ berbanding terbalik dengan kadar $\mathrm{CO}$.

dibutuhkan bahan bakar yang bersih atau murni (tidak ada pengotor) sehingga tidak menghasilkan jelaga dan $\mathrm{CO}$ yang tinggi. Faktor pertimbangan ketiga adalah komposisi oksigen yaitu sebesar 40\%-90\% sesuai stokiometri.

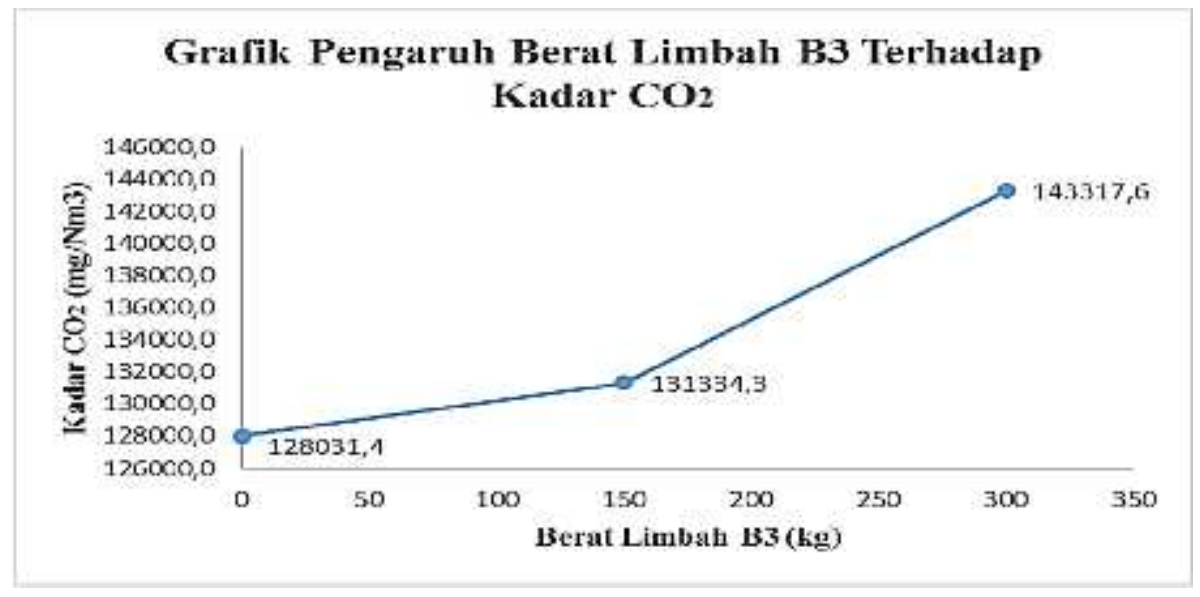

Gambar 3. Pengaruh Berat Limbah B3 Terhadap Kadar $\mathrm{CO}_{2}$

\section{Pengaruh Berat Limbah B3 Terhadap Efisiensi Pembakaran}

Kadar $\mathrm{CO}$ dan $\mathrm{CO}_{2}$ yang diperoleh dapat mempengaruhi nilai efisiensi pembakaran insinerator tersebut dalam mengolah limbah B3. Dari tabel 1 dapat dilihat bahwa pembakaran limbah B3 dengan menggunakan insinerator tipe reciprocating grate incinerator dengan variasi berat limbah B3 yaitu : $0 \mathrm{~kg}, 150 \mathrm{~kg}$, dan $300 \mathrm{~kg}$ semua menghasilkan efisiensi pembakaran (EP) sebesar 99,99\%, dengan demikian pembakaran limbah B3 insinerator tipe reciprocating grate incinerator insinerator tipe reciprocating grate incinerator sudah sesuai dengan peraturan Kep-03/ Bapedal/ 09/ 1995.

Di dalam pembakaran Limbah B3 ini terdapat 2 (dua) kondisi yang berbeda antara insinerator dengan limbah kosong $(0 \mathrm{~kg})$ dan yang memiliki berat ( $150 \mathrm{~kg}$ dan $300 \mathrm{~kg})$. Pada keadaan insinerator kosong kondisi yang diharapkan adalah tidak terdapat kebocoran agar suhu bakar yang dikehendaki pada ruang bakar I yaitu $800^{\circ} \mathrm{C}$ dan pada ruang bakar 2 yaitu $1200^{\circ} \mathrm{C}$, sehingga suhu yang dikehendaki cukup atau mampu untuk mengubah $\mathrm{CO}$ menjadi $\mathrm{CO}_{2}$. Pertimbangan kondisi yang kedua adalah pada bahan bakar untuk menunjang terjadinya pembakaran yang sempurna. Supaya pembakaran yang terjadi sempuran maka

Hal ini ditujukan agar oksigen mampu mengoksidasi atau membakar $\mathrm{CO}$ menjadi $\mathrm{CO}_{2}$. Faktor keempat yang mempengaruhi kualitas pembakaran ini adalah pada waktu tinggal gas pada ruang bakar II, yaitu minimal $2 \mathrm{~s} / \mathrm{d} 6$ detik. Waktu tinggal dipengaruhi oleh desain insinerator, hal ini dikarenakan volume insinerator dengan debit udara berbanding lurus untuk mendapatkan waktu tinggal yang sesuai, besaran waktu tinggal $2 \mathrm{~s} / \mathrm{d} 6$ detik telah sesuai dengan Kep-03/ Bapedal/ 09/1995 (Sutardi, 2011)

Selain itu 4 (empat) faktor di atas, efisiensi pembakaran juga dipengaruhi oleh berat limbah B3 yang dibakar. Limbah B3 tersebut memiliki nilai kalor tertentu yang dapat meningkatkan suhu pembakaran, semakin banyak limbah B3 maka semakin tinggi nilai kalornya hal ini berdampak pada meningkatnya suhu pembakaran yang lebih tinggi dan dapat membantu proses pembakaran lebih sempurna. Hal ini berbanding lurus dengan suhu yang ingin dicapai, karena semakin besar berat limbah B3 yang dibakar maka akan semakin kecil volume ruang bakar yang tersedia sehingga akan mempercepat peningkatan suhu. Dari peningkatan suhu di ruang bakar ini maka 
Adi Moh. Rizal dan Indah Nurhayati :Pengolahan Limbah Bahan Berbahaya Dan Beracun (B3) Dengan Insinerator Tipe Reciprocating Grate Incinerator

dapat mempercepat proses oksidasi atau pembakaran $\mathrm{CO}$ menjadi $\mathrm{CO}_{2}$ sehingga pembakarannya dapat dikatakan lebih sempurna (Sutardi, 2011).

\section{KESIMPULAN}

Dari penelitian ini tentang pembakaran limbah B3 menggunakan insenerator tipe reciprocating grate incinerator disimpulkan bahwa: (1) Kadar $\mathrm{CO}$ hasil pembakaran limbah B3 mulai dari 0 $\mathrm{kg}, 150 \mathrm{~kg}$ dan $300 \mathrm{~kg}$ masih dibawah nilai ambang batas sesuai Kep-03/ Bapedal/ 09/1995 yaitu $100 \mathrm{mg} / \mathrm{Nm}^{3}$. (2) Pembakaran limbah B3 dengan variasi berat limbah B3 yaitu : $0 \mathrm{~kg}, 150$ $\mathrm{kg}$, dan $300 \mathrm{~kg}$ semua menghasilkan efisiensi pembakaran (EP) sebesar 99,99\%, dengan demikian EP sudah sesuai dengan peraturan Kep-03/ Bapedal/ 09/ 1995. (3) Kadar CO dan $\mathrm{CO}_{2}$ dipengaruhi oleh berat limbah $\mathrm{B} 3$, semakin besar berat limbah B3 sampai kapasitas maksimum yang dibakar, kadar $\mathrm{CO}$ semakin menurun sedangkan kadar $\mathrm{CO}_{2}$ semakin meningkat. (4) Efisiensi pembakarannya tidak dipengaruhi oleh variasi berat limbah B3 yang dibakar, berat limbah B3 $(0 \mathrm{~kg}, 50 \mathrm{~kg}$, dan 100 $\mathrm{kg}$ ) yang dibakar semua menghasilkan EP yang sama yaitu $99,99 \%$.

Perlu adanya penelitian lanjutan tentang pengaruh komposisi limbah, jenis limbah dan berat limbah yang dibakar yang melebihi kapasitas incinerator dan juga perlu dilakukan analisis untuk parameter yang lain, seperti: kadar debu, efisiensi pembakaran secara fisik

\section{UCAPAN TERIMAKASIH}

Ucapan terima kasih peneliti sampaikan kepada Universitas PGRI Adi Buana yang sudah memberikan kesempatan kepada peneliti untuk melakukan peneltian. Tidak lupa ucapan terima kasih juga peneliti sampaikan kepada Dra. Indah Nurhayati, ST,MT yang telah memberkan bimbingan dan arahan kepada peneliti demi terselesaikannya penelitian ini.

\section{DAFTAR PUSTAKA}

Girsang, V.E 2013. Evaluasi Pengelolaan Limbah Padat B3 Hasil Insinerasi di RSUD Dr Soetomo Surabaya. Jurnal Teknik POMITS, 02(02), 46-50.

Gusdini, Ninin. 2012. Pengelolaan Limbah B3. Fakultas Teknik. Jakarta: Universitas Sahid Jakarta.

Keputusan Menteri Tenaga Kerja RI No. Kep. 187/Men/1999 Tentang Pengendalian Bahan Kimia Berbahaya di Tempat Kerja

Keputusan Kepala Badan Pengendalian Dampak Lingkungan Nomor 03/Bapedalda/09/1995 Tentang Persyaratan Teknis Pengolahan Limbah Bahan Berbahaya dan Beracun.

Nurhayati, I. \& Triastuti, S.A. 2011. Pengolahan Sampah Medis Jarum RS. DR. Sutomo Surabaya dengan Incenerator Modifikasi. Jurnal Teknik WAKTU 09 (01), 25-33.

Peraturan Pemerintah Nomor 101 Tahun 2014 Tentang Pengelolaan Limbah Bahan Berbahaya dan Beracun.

Sutardi, T. 2011. Combustion Technique \& Gaseous Emission Monitoring. Bogor.

Unites States Enviromental Protection Agency, 2006. Method 10 - determination of Carbon Monoxide Emission from Stationary Source.

Zulhijjah, J. 2014. Efektifitas Pemusnahan Limbah B3 (Bahan Berbahaya dan Beracun) Secara Thermal (Insinerasi). Skripsi. Jakarta : Universitas Sahid Jakarta. 